\title{
Electrospun Polyamide 4.6 Nanofibrous Nonwovens: Parameter Study and Characterization
}

\section{Bert De Schoenmaker, Lien Van der Schueren, Özgür Ceylan, and Karen De Clerck}

Department of Textiles, Ghent University, Technologiepark 907, 9052 Ghent, Belgium

Correspondence should be addressed to Karen De Clerck, karen.declerck@ugent.be

Received 14 December 2011; Accepted 16 February 2012

Academic Editor: Tong Lin

Copyright (C) 2012 Bert De Schoenmaker et al. This is an open access article distributed under the Creative Commons Attribution License, which permits unrestricted use, distribution, and reproduction in any medium, provided the original work is properly cited.

The aliphatic polyamide 4.6 (PA 4.6) has unique properties compared to the commonly used polyamides 6 (PA 6) and 6.6 (PA 6.6). The purpose of this paper is to produce uniform and reproducible nanofibrous PA 4.6 structures. Therefore, a mixture of the solvent formic acid and the nonsolvent acetic acid is used to dissolve and electrospin the PA 4.6. First the steady-state behaviour of the process and the boundary limits of the solution parameters needed for steady-state electrospinning are investigated. Subsequently, the effect of several solution and process parameters on the fibre morphology is examined, using microscopic techniques and thermal analysis. The polyamide concentration is found to be the dominant parameter affecting the fibre diameter and morphology. Furthermore, tensile tests are performed on upscaled nanofibrous structures and electrospun under optimised steady-state conditions. It is shown that the PA 4.6 nanofibrous structures, compared to nanofibrous nonwovens of PA 6 and PA 6.6, have a higher stress and strain at break.

\section{Introduction}

Nanofibres, with a fibre diameter smaller than $500 \mathrm{~nm}$, offer major potentials through specific and unique characteristics. Nanofibres have a high specific surface, small pore sizes, and high porosity [1]. Furthermore, nanofibrous structures also have a low surface roughness [2], a superior mechanical performance [3], a high liquid absorption capacity [4], and higher wicking rates [5]. Thanks to this variety in properties, many applications are possible. Nanofibrous mats are used in biomedical applications $[6,7]$ such as prostheses, tissue templates [8], wound dressings [9], and drug release systems. As filter efficiency is directly related with the fibre fineness, filtration is yet another promising application $[10,11]$. The electrospun nanofibres can also be applied in protective clothing [12], in composites [13, 14], and in electrical and optical devices [15].

Nanofibres can be produced by a wide range of methods [16], but the most promising method to obtain uniform nanofibrous structures with a narrow fibre distribution is nozzle solvent electrospinning [17]. In this method the polymer solution is pumped from a closed reservoir through a nozzle in an electric field. Due to this electric field and the intrinsic charges of the solution, the polymer jet bends, stretches, and splits, resulting in a nanofibrous nonwoven. The nozzle-electrospun method has a significant lower nanofibre distribution compared to the bubble electrospinning $[18,19]$ or nozzle free electrospinning methods $[20,21]$.

To produce nanofibres in a reproducible way on a larger industrial scale, it is absolutely necessary that the properties of the nanofibrous nonwoven are constantly guaranteed. Electrospinning, under steady-state conditions [5, 22, 23], guarantees this key prerequisite as it is essential in nozzle electrospinning to obtain a stable production process that fabricates a uniform reproducible nonwoven. Three conditions have to be fulfilled. All the amount of polymer brought in the electric field per time unit is to be deposited as nanofibres on the collector plate per time unit, the Taylor cone is stable as a function of time, and the nanofibres have to be deposited on a well-defined area below the nozzle. Thanks to these steadystate conditions, frequently observed electrospinning problems can be avoided, such as clogging, drops, beads, or heterogeneity in the thickness of the nonwoven. 
Polyamide (PA) 4.6 is an aliphatic polyamide which has attractive properties compared to PA 6 and PA 6.6. This polymer has a higher melting temperature $\left(290^{\circ} \mathrm{C}\right)$ and a higher crystallinity $(60-70 \%)$ compared to other polyamides [24, 25 ] thanks to its highly symmetrical molecular structure and high amount of amide groups per unit of chain length. Moreover, PA 4.6 also has excellent mechanical properties particularly at high temperatures such as high stiffness, good toughness, and high creep resistance $[25,26]$. In addition, PA 4.6 absorbs more water than the other polyamides, even though it has a higher crystallinity [26]. Most of these properties offer advantages for nanofibre applications: the high hydrophilicity for filtration and the better mechanical properties for composites [27].

Literature on electrospinning of PA 4.6 is very confined $[13,27,28]$. Moreover, none of the articles report on the stability of the process nor on the influence of the electrospinning parameters on the fibre morphology. With the process stability being a crucial parameter for future potentials, the present paper focuses on the steady-state electrospinning of PA 4.6. Therefore PA 4.6 is dissolved in mixtures of the solvent formic acid and the nonsolvent acetic acid. Starting from this solvent mixture a steady-state table is composed, which summarizes the combinations of solvent ratios and polyamide concentrations that can be electrospun without irregularities. An understanding of the boundary conditions for steady-state electrospinning allows for reproducible sample preparations needed for a reliable fibre morphology analysis. Such fibre morphology information may in return provide more insight into the driving forces of the steadystate behaviour. Thus the second part of the paper focuses on the fibre morphology, by scanning electron microscopy (SEM) and differential scanning calorimetry (DSC), of the steady-state spun nanofibres with varying parameters within the steady-state window. Finally the mechanical behaviour of the PA 4.6 nanofibrous nonwovens is investigated and compared with PA 6 and PA 6.6 nanofibrous nonwovens.

\section{Materials and Methods}

PA 4.6 (Mw: 80,000), PA 6 (Mw: 50,000), PA 6.6 (Mw: 60,000), 98-100 v\% formic acid and 99,8 v\% acetic acid were obtained from Sigma-Aldrich and used as received. The electrospinning solutions were prepared by dissolving different polyamide concentrations in various ratios of formic acid and acetic acid and gently stirred overnight.

Prior to electrospinning the viscosity and conductivity of the electrospinning solutions were examined using a Brookfield viscometer LVDV-II and a CDM210 conductivity meter of Radiometer Analytical, respectively.

The mononozzle electrospinning setup comprised a high voltage source (Glassman High Voltage Series EH30P3), an infusion pump (KD Scientific Syringe Pump Series 100), a $20 \mathrm{~mL}$ syringe (Henke SassWolf), and a grounded collector plate. The polymer solution was pumped through a $15.24 \mathrm{~cm}$-long needle (Sigma Aldrich), with an inner diameter of $1.024 \mathrm{~mm}$, in the electric field. The tip-to-collector distance was adjusted through a laboratory jack. A potential difference was set between the tip of the needle and the grounded collector plate. The electrospinning room was conditioned at a temperature of $23^{\circ} \mathrm{C}$ and a relative humidity of $50 \%$.

The steady-state behaviour is represented in a steadystate table. The columns represent the percentage acetic acid and the rows respresents the PA 4.6 concentration. The tip-to-collector distance (TCD) and flow rate were fixed at $10 \mathrm{~cm}$ and $2 \mathrm{~mL} / \mathrm{h}$, respectively, since these parameter values resulted in a broad steady-state window. The applied voltage was varied and optimised to obtain uniform, reproducible nanofibrous structures. Typically a range of $5 \mathrm{kV}$ allowed for steady-state conditions with the lower limit shown in the table. Such a steady-state table consists of three regions: one region for which the pellets are not dissolved, one for which the pellets are dissolved but still the solution is not electrospinnable, and the most important region, the steady-state window, for which all the requirements are fulfilled to obtain uniform nanofibrous structures.

The samples used for the tensile tests were produced on a multinozzle setup, based on in-house developed technology and described elsewhere [29]. The multinozzle method mainly diverges from the mononozzle setup by the number of nozzles, with the general methodology remaining the same. Nozzles, each fed by a syringe, were fixed in alternating rows and moved in the width direction. Meanwhile, a collector was moving in the production (or length) direction. This multinozzle setup delivered nanofibrous nonwovens sufficiently large and reproducible to allow for a large set of tensile test samples.

The morphology of the electrospun nanofibres was examined using an SEM, Joel Quanta 200 F FE-SEM. Prior to SEM analysis, the samples were coated with gold, using a sputter coater (Balzers Union SKD 030). The average fibre diameter and their standard deviations were based on 50 measurements, using Cell ${ }^{\mathrm{D}}$ software from Olympus.

The analysis of the thermal behaviour was performed by DSC, using a Q2000 from TA Instruments. Samples of $2 \pm 0.2 \mathrm{mg}$ were placed in appropriate sealed standard Tzero aluminium pans. The experiments were performed from 0 to $325^{\circ} \mathrm{C}$, with a heating rate of $10^{\circ} \mathrm{C} / \mathrm{min}$, under a constant nitrogen flow of $50 \mathrm{~mL} / \mathrm{min}$. The results were analyzed using the TA Universal Analysis software package.

The tensile tests, using a Favimat (Textechno), are executed on samples prepared by the multi-nozzle production method as to obtain large enough samples that allow proper testing. All experiments were run in the direction perpendicular to the production direction (cross-direction). Testing of the samples parallel to the production direction resulted sometimes in a delamination effect leading to possible erroneous interpretation of the tensile tests. As delamination did not occur in the cross-direction, this direction was chosen for further testing of all samples. For each polyamide type 80 samples of 4 by $30 \mathrm{~mm}$ were tested. The gauge length and test speed were $20 \mathrm{~mm}$ and $20 \mathrm{~mm} / \mathrm{min}$, respectively. The properties of the three nanofibrous nonwovens are given in Table 1. Three nanofibrous samples of $10 \mathrm{~cm}$ by $10 \mathrm{~cm}$ were weighted to calculate the average grammage of the different nanofibrous structures. The porosity was theoretically determined 
TABLE 1: Properties of the various nanofibrous structures.

\begin{tabular}{lccc}
\hline Type PA & $\begin{array}{c}\text { Grammage } \\
{\left[\mathrm{g} / \mathrm{m}^{2}\right]}\end{array}$ & $\begin{array}{c}\text { Nanofibre diameter } \\
{[\mathrm{nm}]}\end{array}$ & $\begin{array}{c}\text { Porosity } \\
{[\%]}\end{array}$ \\
\hline PA 4.6 & 50 & $203 \pm 18$ & 90.02 \\
PA 6 & 49 & $160 \pm 15$ & 90.24 \\
PA 6.6 & 54 & $143 \pm 29$ & 92.25 \\
\hline
\end{tabular}

TABLE 2: Steady-state table, showing the steady-state window for which the lower limits of the required voltage $(\mathrm{kV})$ are given to obtain steady-state behaviour. TCD: $10 \mathrm{~cm}$, flow rate: $2 \mathrm{~mL} / \mathrm{h}$.

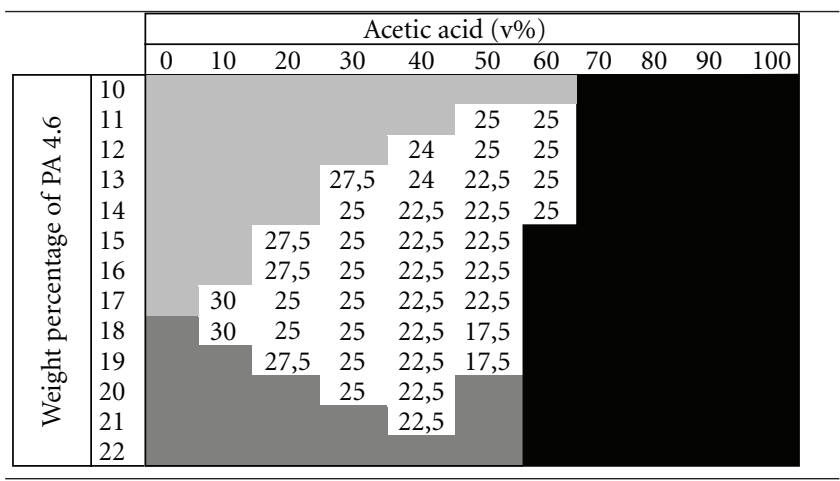

out of the density of the nonwovens and their respective bulk density.

\section{Results and Discussion}

3.1. Steady-State Window. Formic acid and acetic acid are used as solvents for electrospinning PA 4.6 since mixtures of both acids were advantageous for other polyamides [22, $30,31]$. Although acetic acid is not a solvent for PA 4.6 , it is added to stabilize the electrospinning solutions [32]. Without the nonsolvent acetic acid the solution properties of the overall solution are not suitable to electrospin PA 4.6 in a broad parameter window $[22,30]$.

Within the steady-state table, Table 2 , three regions are distinguished. For the light grey area and the dark grey area, combined as one region, all polymer is dissolved but no uniform nanofibres can yet be produced. In this region the main amount of polymer is deposited as drops and beads on the collector plate, and only a few fibres are formed. The viscosity is the key parameter in this phenomenon with the viscosity being too small for the light grey area and too high for the dark grey area. Table 3 shows that the viscosity increases with increasing polymer concentration, from $137 \mathrm{mPa} \cdot \mathrm{s}$ for $8 \mathrm{wt} \% \mathrm{PA} 4.6$ to $2165 \mathrm{mPa} \cdot \mathrm{s}$ for $18 \mathrm{wt} \% \mathrm{PA} \mathrm{4.6.} \mathrm{On} \mathrm{the}$ other hand, this increasing polymer concentration does not strongly affect the conductivity of the electrospinning solutions, (see Table 3 ). The region enclosing the black area is characterized by an incomplete dissolubility of the polymer due to the high amount of acetic acid.

The region enclosing the white area, or the steady-state window, as within this window, where very uniform and reproducible nanofibres are obtained, without any irregularity,
TABLE 3: The measured viscosity and conductivity for different PA 4.6 solutions.

\begin{tabular}{lccc}
\hline $\begin{array}{l}\text { Concentration PA } \\
4.6(\mathrm{wt} \%)\end{array}$ & $\begin{array}{c}\text { Concentration } \\
\text { acetic acid }(\mathrm{v} \%)\end{array}$ & $\begin{array}{r}\text { Viscosity } \\
(\mathrm{mPa} \cdot \mathrm{s})\end{array}$ & $\begin{array}{c}\text { Conductivity } \\
(\mathrm{mS} / \mathrm{cm})\end{array}$ \\
\hline 8 & 50 & 137 & 0.646 \\
10 & 50 & 278 & 0.677 \\
12 & 50 & 517 & 0.676 \\
14 & 50 & 916 & 0.663 \\
16 & 50 & 1434 & 0.621 \\
18 & 50 & 2165 & 0.625 \\
14 & 0 & 913 & 3.405 \\
14 & 10 & 986 & 2.787 \\
14 & 20 & 885 & 2.021 \\
14 & 30 & 811 & 1.391 \\
14 & 40 & 998 & 0.976 \\
14 & 60 & 852 & 0.389 \\
\hline
\end{tabular}

is the area of interest. For these solutions a set of process conditions can be found that allow for the steady-state electrospinning of nanofibres. With the TCD and flow rate set at fixed values, the applied voltage was varied to obtain steadystate behaviour. The boundary PA 4.6 concentration limits are altered with the solvent ratio, mainly due to a combined effect of viscosity, surface tension, and conductivity variations of the resultant solutions. Indeed a variation in solvent ratio mainly results in a variation in conductivity whereas a variation in polymer concentration is mainly observed in the viscosity, Table 3, in agreement with literature [33].

Overall, the required applied voltage decreases with increasing amount of acetic acid and with increasing polymer concentration. For a constant polymer concentration a variation in formic acid/acetic acid ratio results in relevant changes in electric properties of the solvent mixtures, since formic acid and acetic acid have dielectric constants of 57.2 and 6.6, respectively, [34] and conductivities of $157 \mu \mathrm{S} / \mathrm{cm}$ and $0 \mu \mathrm{S} / \mathrm{cm}$, respectively [30]. These results show that the required applied voltage decreases with a decreasing dielectric constant and conductivity. For a constant solvent ratio the variations in required applied voltage are less explicit with varying polymer concentration, which is in agreement with the constant conductivity of Table 3 .

In literature polyamides are frequently electrospun from a pure formic acid solution [35,36]; however, Table 2 clearly shows that adding the nonsolvent acetic acid substantially broadens the polymer concentration range. It allows for an increased process stability window. This broad stability window offers the possibility to study the fibre morphology with varying electrospinning parameters, as a set of reproducible steady-state samples can be compared. Thus not only a fibre characterisation but also more insight into the driving forces of the steady-state behaviour is aimed.

\subsection{Fibre Morphology as a Function of Electrospinning Parameters}

3.2.1. Polymer Concentration. A fixed ratio of $50 \mathrm{v} \%$ formic acid and $50 \mathrm{v} \%$ acetic acid was chosen to investigate the influence of the PA 4.6 concentration on the average fibre 


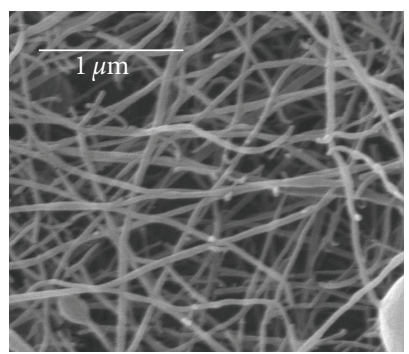

(a)

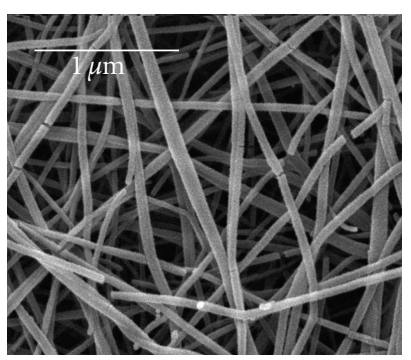

(b)

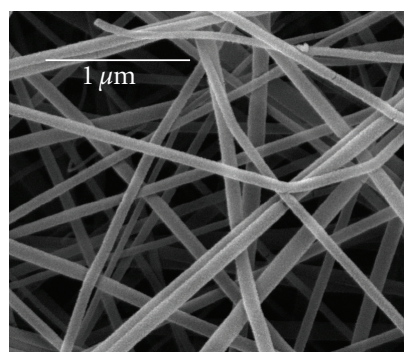

(c)

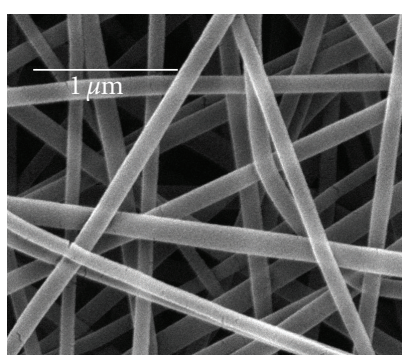

(d)

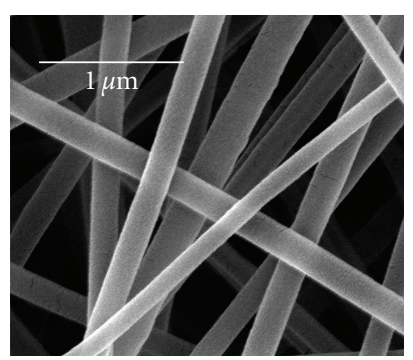

(e)

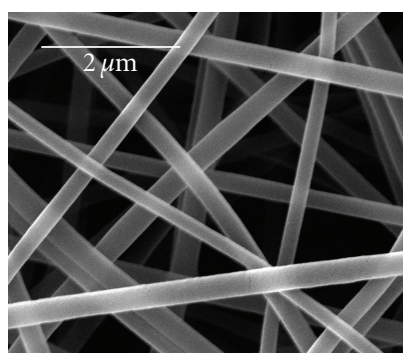

(f)

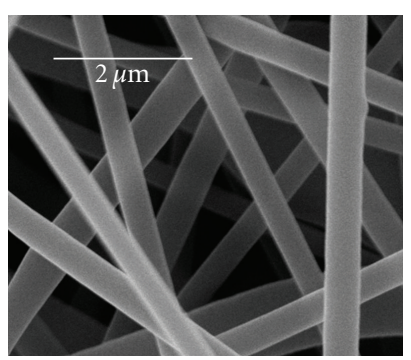

$(\mathrm{g})$

Figure 1: SEM images of different polymer concentrations: $6 \mathrm{wt} \%$ (a), $8 \mathrm{wt} \%$ (b), $10 \mathrm{wt} \%$ (c), $12 \mathrm{wt} \%$ (d), $14 \mathrm{wt} \%$ (e), $16 \mathrm{wt} \%$ (f), and $18 \mathrm{wt} \%$ (g). TCD: $10 \mathrm{~cm}$ and flow rate: $2 \mathrm{~mL} / \mathrm{h}$.

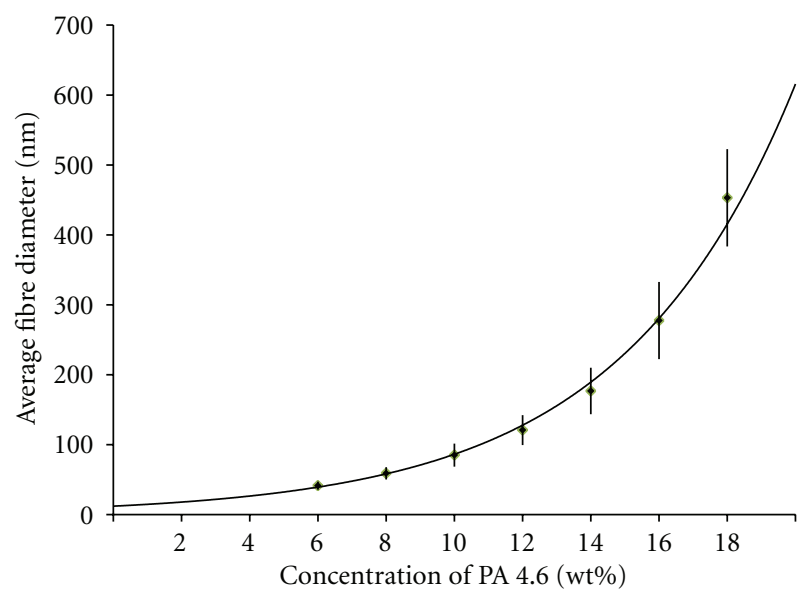

Figure 2: Influence of the PA 4.6 concentration on the average fibre diameter.

diameter. SEM images (Figure 1) illustrate that all studied nanofibres are characterised by smooth uniform surfaces. Although the concentrations below $11 \mathrm{wt} \%$ did not allow for steady-state electrospinning, they could be electrospun for a shorter time in a stable manner. It is important to keep in mind that these lower concentrations are not electrospun under steady-state conditions, and some irregularities may thus appear. Figure 2 clearly shows that the nanofibre diameter increases with increasing polymer concentration, following an overall exponential trend.

The fibre distribution is not influenced by the polymer concentration, being typically around $15 \%$ for all samples. This demonstrates that the nozzle solvent electrospinning technology allows production of high-quality nanofibrous
PA 4.6 structures with a narrow fibre diameter distribution. It has to be emphasised that such small distributions are difficult to reach with other electrospinning methods $[37,38]$. Even the appearance of drops in the first three nanofibrous nonwovens (6 to $10 \mathrm{wt} \%$ ) has no significant influence on this fibre diameter distribution.

It is clear that the polymer concentration is an ideal parameter to tune the required fibre diameter. However a key prerequisite is the proper use of the mixture of the solvent formic acid and the nonsolvent acetic acid as this broadens the range of polymer concentration that can be electrospun under steady-state conditions.

3.2.2. Solvent Ratio. The polymer concentration is fixed at $12 \mathrm{wt} \%$ to investigate the influence of the amount of nonsolvent acetic acid on the fibre morphology. This allows to compare samples well within the steady-state window and on the border or outside the steady-state window. The $20 \%$ and $30 \%$ acetic acid mixtures did not fulfil the steady-state conditions, as the Taylor cone was not stable in time. To minimise the nonsteady-state behaviour and drop formation, a voltage of $30 \mathrm{kV}$ was applied. SEM images (Figure 3) illustrate that although some very small drops are still present, it is yet possible to assign a characteristic average fibre diameter to these nanofibrous nonwovens. A voltage of $30 \mathrm{kV}$ was also applied to the other solvent mixtures as to keep this parameter constant, and it did allow for steady-state electrospinning at these higher acetic acid concentrations.

For the lower concentrations of acetic acid, below the limits of the steady-state window, the average fibre diameter is significantly smaller than for the higher concentrations of acetic acid (Figure 4). This might be attributed to the amount of irregularities in these structures; however this does not 


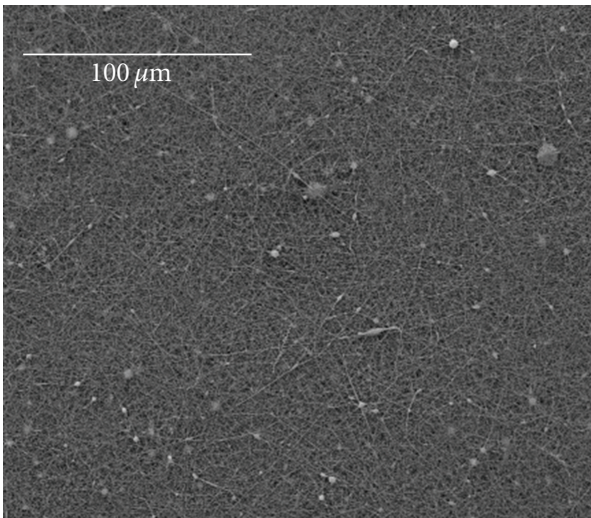

(a)

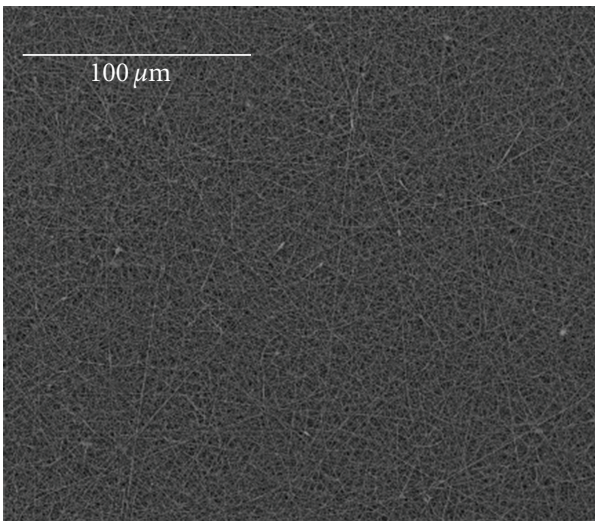

(b)

Figure 3: SEM images of $12 \mathrm{wt} \%$ PA 4.6 electrospun from a formic acid/acetic acid solution with $20 \mathrm{v} \%$ acetic acid (a) and $30 \mathrm{v} \%$ acetic acid (b).

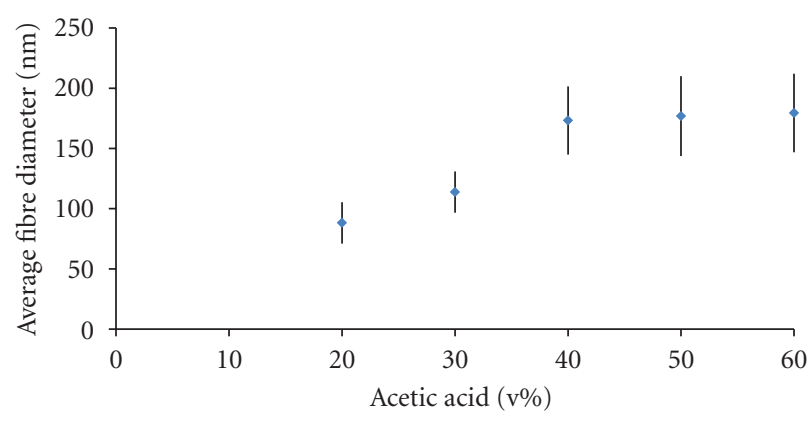

FIGURE 4: Influence of the percentage acetic acid on the average fibre diameter.

clarify the small fibre diameter distribution. Moreover, also within the steady-state window a small decrease of the fibre diameter is observed. A decreased acetic acid concentration results in an increased dielectric constant and conductivity which affect the electrospinning process. An increased dielectric constant and conductivity, and thus increased Coulombic repulsion forces and electrostatic forces, lead to an increased bending, splitting, and stretching and thus to finer fibres. This is in agreement with similar findings for various

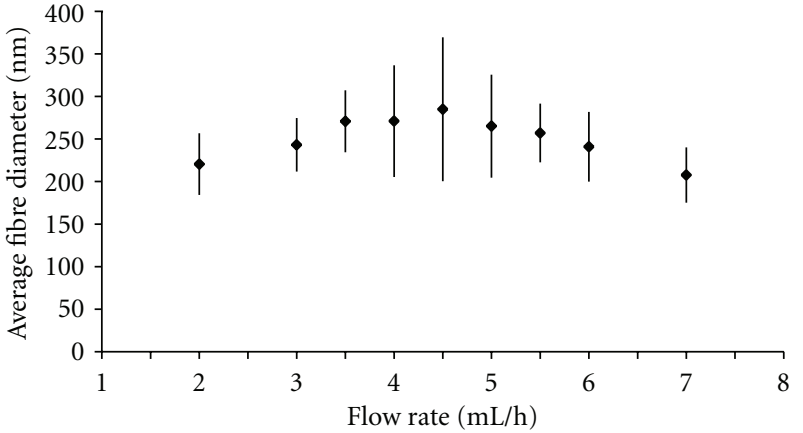

Figure 5: Influence of the flow rate on the average fibre diameter and standard deviation.

polymer-solvent combinations $[39,40]$. Thus, although lower percentages of acetic acid allow for finer fibres, a minimal amount is needed to obtain reproducible high-quality nanofibrous nonwovens. Moreover, within the steady-state window the polymer concentration is a more appropriate parameter to tune the fibre diameter.

3.2.3. Process Parameters. To study the effect of flow rate, applied voltage, and TCD the $14 \mathrm{wt} \%$ PA 4.6 in a mixture of $50 \mathrm{v} \%$ formic acid and $50 \mathrm{v} \%$ acetic acid was chosen. While varying one of these process parameters, the other two parameters were set at fixed values, a flow rate of $2 \mathrm{~mL} / \mathrm{h}$, an applied voltage of $27.5 \mathrm{kV}$ and a TCD of $10 \mathrm{~cm}$. The flow rate only had a very minor effect on the average fibre diameter. With increasing flow rate, an initial increment in average fibre diameter is followed by a decrement (Figure 5). The increased fibre diameter is caused by the greater solution volume that is drawn from the needle tip. Due to the increasing amount of charges with an increasing flow rate, there are limits to this increase in the fibre diameter [17]. The effect on standard deviation is larger with it reaching a maximum at the maximum fibre diameter. This may possibly be assigned to a change in the dominant driving mechanisms (stretching versus splitting) during the fibre formation process.

The applied voltage was studied over a range from $12.5 \mathrm{kV}$ to $30 \mathrm{kV}$, for both a flow rate of $2 \mathrm{~mL} / \mathrm{h}$ and $4 \mathrm{~mL} / \mathrm{h}$. It is important to realise that below $20 \mathrm{kV}$, no stable Taylor cone could be obtained for longer times. Although relatively drop-free samples could be obtained with an initial stable Taylor cone, some smaller fibrils or "branches" appear (Figure 6(a)). Overall the fibre diameter increases with increased voltage, with a somewhat stepwise increase once the voltage has reached the minimum for steady-state conditions [41], Figure 7. For a higher flow rate, the applied voltage to obtain steady-state has to be slightly higher, as shown in Figure 7. For $4 \mathrm{~mL} / \mathrm{h}$ the stepwise increase shifted to a slightly higher applied voltage compared to $2 \mathrm{~mL} / \mathrm{h}$. Due to the higher applied voltage the time to stretch the fibres is smaller, resulting in thicker nanofibres. Moreover, Figure 7 indicates that the steady-state window differs by changing the flow rate. Within the steady-state region the effect is only minor. The flow rate only shows a minor effect in agreement with the results in Figure 5, except for the $20 \mathrm{kV}$ 


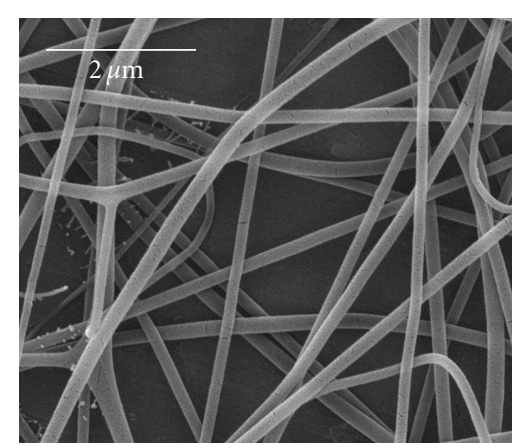

(a)

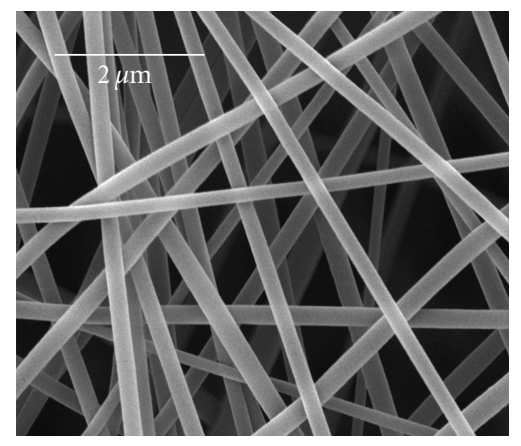

(c)

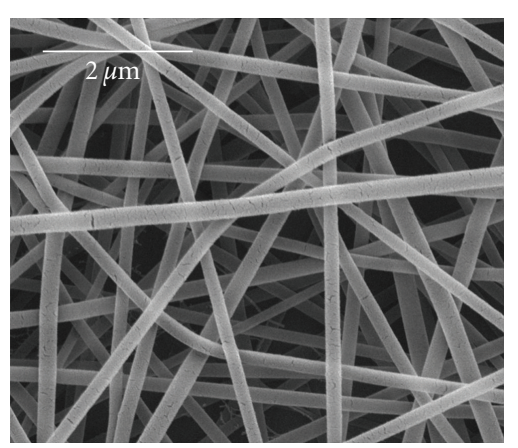

(b)

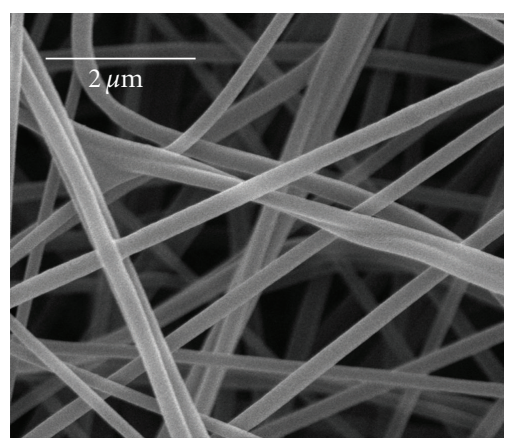

(d)

FIGURE 6: SEM images of different applied voltages: $12.5 \mathrm{kV}$ (a), $17.5 \mathrm{kV}$ (b), $22.5 \mathrm{kV}$ (c) and $27.5 \mathrm{kV}$ (d).

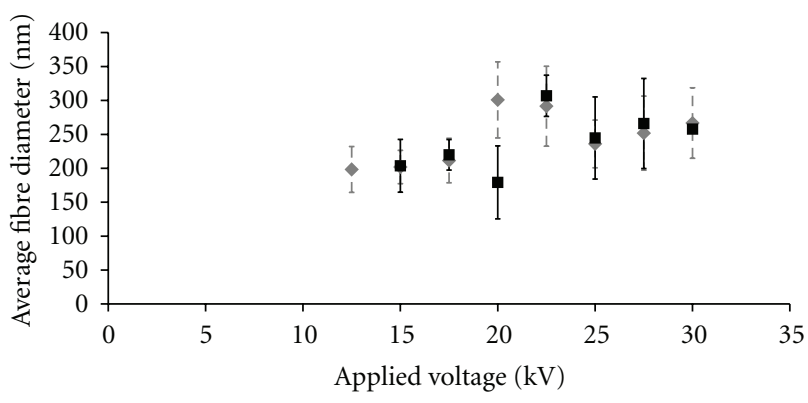

FIGURE 7: Influence of the applied voltage on the average fibre diameter for two flow rates: $(\checkmark) 2 \mathrm{~mL} / \mathrm{h}$ and $(\boldsymbol{\square}) 4 \mathrm{~mL} / \mathrm{h}$.

sample for which a larger difference in fibre diameter with flow rate is observed. This is likely to be attributed to a slight difference in the minimal required voltage to reach steady-state conditions at these two different flow rates.

The third investigated process parameter was the TCD (Figure 8). For a TCD above $13 \mathrm{~cm}$ the stability of the Taylor cone was no longer guaranteed although the SEM images did not show major irregularities. Well within the steadystate window (a TCD below $13 \mathrm{~cm}$ ) only minor variations are observed in the fibre diameter. This is in line with the minor variation in fibre diameter with varying applied voltage as both the applied voltage and the TCD are related through the field strength. Exceeding the TCD above the limits (above 15) for steady-state conditions results in a decrease in fibre diameter. This is in line with the decrease in fibre diameter

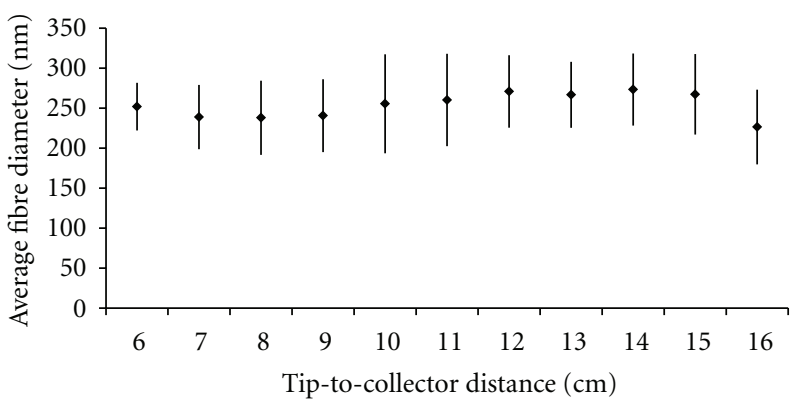

FIGURE 8: Influence of the tip-to-collector distance on the average fibre diameter.

with an applied voltage below the limits for steady-state (Figure 7).

Thus within the steady-state window all studied process parameters only have a minor effect on the fibre diameter and morphology compared to the solution parameters. They are, however, very important and need to be well chosen as to reach steady-state conditions. Indeed electrospinning under process conditions out of the steady-state window does result in significant variations in fibre diameter and more importantly in less reproducible samples.

3.3. Thermal Analysis. Differential scanning calorimetry on the electrospun nanofibrous structures shows a multiple melting behaviour with two dominant peaks at $285^{\circ} \mathrm{C}$ and at $289^{\circ} \mathrm{C}$ to $293^{\circ} \mathrm{C}$ (Figure 9). An increased concentration of 


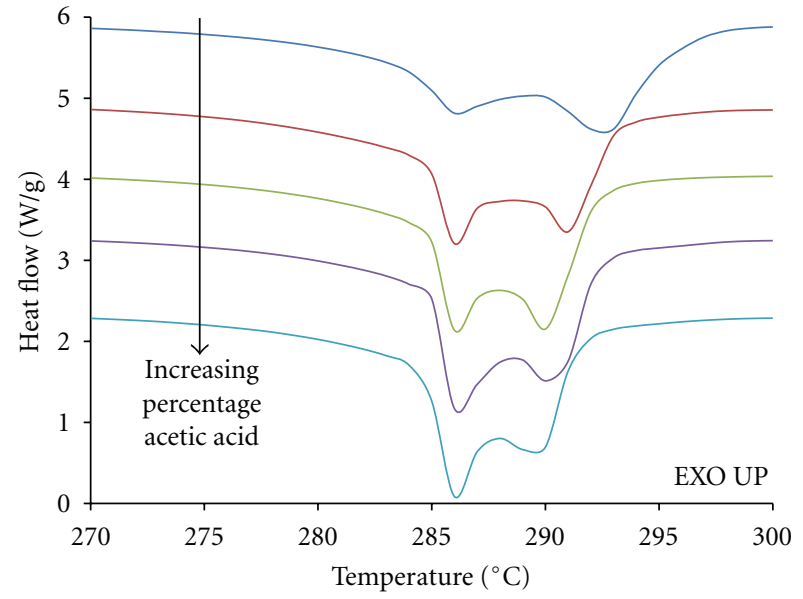

FIGURE 9: Melting behaviour of nanofibres electrospun with different solvent ratios. The fraction acetic acid increases from $20 \mathrm{v} \%$ to $60 \mathrm{v} \%$.

acetic acid results in a shift of the melting profile to lower temperatures with this being most explicit for the hightemperature melting peak. Also a relative decrease of the high-temperature melting transition in favour of the low temperature melting transition is to be observed. Moreover the fibres electrospun at higher concentration acetic acid show a small recrystallization exotherm before the melting profile which is no longer visible for the lowest acetic acid concentration. Indeed, the larger diameters with the higher acetic acid concentration support a lower stretching of the fibres, in line with the higher amount of less stable crystal phase as suggested by the DSC results. This shows that an increasing concentration acetic acid not only increases the fibre diameter but also changes the crystal morphology. The changes in the morphology are not to be attributed to a degradation since the second heating runs nicely overlap for all samples. Thus the observed variations in the fibre and crystal morphology are a consequence of the concentration of acetic acid. These changes in the crystal morphology, related to the fibre diameter, are in line with our previous findings for PA 6.9 [30] and PA 6 [31], in which the results for the effect of polymer concentration were described.

3.4. Tensile Tests. The mechanical properties of the PA 4.6 nanofibrous nonwovens are compared to those of PA 6 and PA 6.6, the two most frequently used polyamides. Figure 10 clearly shows that PA 4.6 nanofibrous nonwovens have the highest strain and tensile strength at break. PA 4.6 is known to offer superior mechanical properties compared to PA 6 or PA $6.6[24,25]$. These superior mechanical properties also show for the nanofibrous samples with its substantial higher stress and strain at break. The original modulus of the PA 4.6 nanofibrous structures is however somewhat lower compared to the PA 6 and PA 6.6 samples. This is in line with literature on melt extrusion in which also lower moduli are obtained than expected from the material properties [24]. This may indicate that the orientation and crystal morphology induced during the electrospinning process affect the

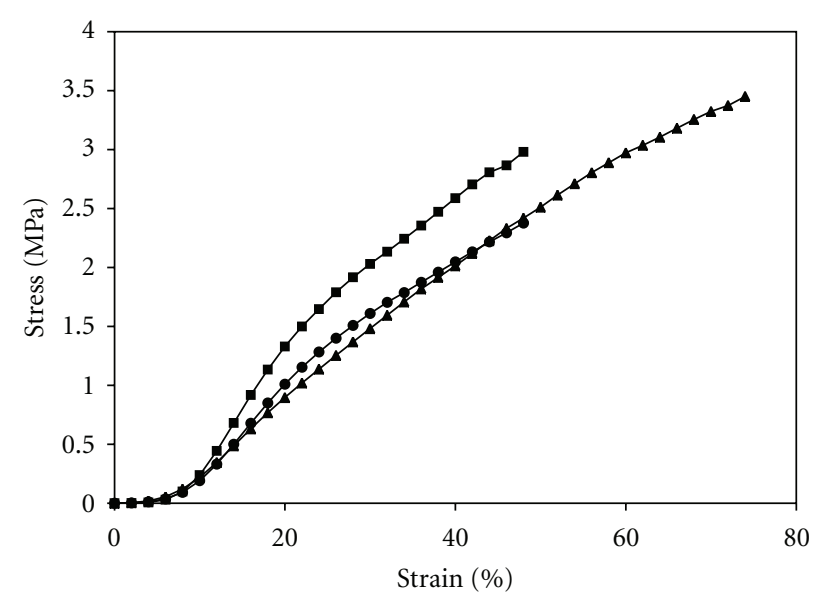

Figure 10: Stress-strain curves of PA $4.6(\boldsymbol{\Delta})$, PA $6.6(\bullet)$, and PA 6 (ם) nanofibrous nonwovens, in cross-direction.

final mechanical properties. This is to be taken into account for future more detailed studies in combination with the effect of web structure on the mechanical properties.

\section{Conclusion}

The present research discusses the steady-state conditions for the electrospinning of PA 4.6 from a solvent mixture containing the solvent formic acid and the nonsolvent acetic acid.

The steady-state window revealed that a minimal concentration of nonsolvent acetic acid is needed to obtain steadystate electrospinning. Solutions with a concentration of $50 \mathrm{v} \%$ acetic acid lead to the broadest polymer concentration range and still allow for steady-state spinning.

Moreover the fibre morphology variations with electrospinning parameters are studied. The polymer concentration is assigned to be the key parameter to tune the fibre diameter. The percentage of nonsolvent acetic acid in the solutions as well as the process parameters are essential to reach steadystate. Within the steady-state window these parameters only have a minor effect on the fibre morphology. However, outside the steady-state window they do substantially affect the fibre morphology and also lead to irregularities.

DSC shows not only the fibre morphology, with diameter as key parameter, to be affected by the solution parameters but also the polymer crystal morphology.

The tensile tests confirm that the PA 4.6 nanofibrous nonwovens have a higher tensile strength and strain at break than the tested PA 6 and PA 6.6 nonwovens.

\section{References}

[1] Y. C. Ahn, S. K. Park, G. T. Kim et al., "Development of high efficiency nanofilters made of nanofibers," Current Applied Physics, vol. 6, no. 6, pp. 1030-1035, 2006.

[2] S. De Vrieze, P. Westbroek, T. Van Camp, and L. Van Langenhove, "Electrospinning of chitosan nanofibrous structures: feasibility study," Journal of Materials Science, vol. 42, no. 19, pp. 8029-8034, 2007. 
[3] Z.-M. Huang, Y.-Z. Zhang, M. Kotaki, and S. Ramakrishna, "A review on polymer nanofibers by electrospinning and their applications in nanocomposites," Composites Science and Technology, vol. 63, no. 15, pp. 2223-2253, 2003.

[4] J. Fang, H. Niu, T. Lin, and X. Wang, "Applications of electrospun nanofibers," Chinese Science Bulletin, vol. 53, no. 15, pp. 2265-2286, 2008.

[5] B. De Schoenmaker, L. Van Der Schueren, S. De Vrieze, P. Westbroek, and K. De Clerck, "Wicking properties of various polyamide nanofibrous structures with an optimized method," Journal of Applied Polymer Science, vol. 120, no. 1, pp. 305-310, 2011.

[6] S. Agarwal, J. H. Wendorff, and A. Greiner, "Use of electrospinning technique for biomedical applications," Polymer, vol. 49, no. 26, pp. 5603-5621, 2008.

[7] B. S. Jha, E. A. Chantal, R. B. James et al., "Electrospun collagen: a tissue engeneering scaffold with unique functional properties in a wide variety of applications," Journal of Nanomaterials, vol. 2011, Article ID 348268, 15 pages, 2011.

[8] L. Li, Y. Li, J. Li et al., "Antibacterial properties of nanosilver PLLA fibrous membranes," Journal of Nanomaterials, vol. 2009, Article ID 168041, 5 pages, 2009.

[9] C. Xu, F. Xu, B. Wang, and T. Lu, "Electrospinning of poly(ethylene-co-vinyl-alcohol) nanofibres encapsulated with Ag nanoparticles for wound healing," Journal of Nanomaterials, vol. 2011, Article ID 201834, 7 pages, 2011.

[10] R. Gopal, S. Kaur, Z. Ma, C. Chan, S. Ramakrishna, and T. Matsuura, "Electrospun nanofibrous filtration membrane," Journal of Membrane Science, vol. 281, no. 1-2, pp. 581-586, 2006.

[11] O. Jirsak, P. Sysel, F. Sanetrnik, J. Hruza, and J. Chaloupek, "Polyamic acid nanofibers produced by needleless electrospinning," Journal of Nanomaterials, vol. 2010, Article ID 842831, 6 pages, 2010.

[12] D. Smidt and D. H. Reneker, PCT/US00/27737, 2001.

[13] C. Huang, S. Chen, C. Lai et al., "Electrospun polymer nanofibres with small diameters," Nanotechnology, vol. 17, no. 6, pp. 1558-1563, 2006.

[14] H. Dodiuk-Kenig, K. Lizenboim, S. Roth et al., "Performance enhancement of dental composites using electrospun nanofibers," Journal of Nanomaterials, vol. 2008, Article ID 840254, 6 pages, 2008.

[15] I. D. Norris, M. M. Shaker, F. K. Ko, and A. G. MacDiarmid, "Electrostatic fabrication of ultrafine conducting fibers: polyaniline/polyethylene oxide blends," Synthetic Metals, vol. 114, no. 2, pp. 109-114, 2000.

[16] W. E. Teo and S. Ramakrishna, "A review on electrospinning design and nanofibre assemblies," Nanotechnology, vol. 17, no. 14, pp. R89-R106, 2006.

[17] S. Ramakrishna, K. Fujihara, W. E. Teo, T. C. Lim, and Z. $\mathrm{Ma}$, An Introduction to Electrospinning and Nanofibres, Workd Scientific, 2005.

[18] R. Yang, J. He, L. Xu, and J. Yu, "Bubble-electrospinning for fabricating nanofibers,” Polymer, vol. 50, no. 24, pp. 58465850, 2009.

[19] Y. Liu, L. Dong, J. Fan, R. Wang, and J. Y. Yu, "Effect of applied voltage on diameter and morphology of ultrafine fibers in bubble electrospinning," Journal of Applied Polymer Science, vol. 120, no. 1, pp. 592-598, 2011.

[20] M. H. El-Newehy, S. S. Al-Deyab, E. -R. Kenawy, and A. AbdelMegeed, "Nanospider technology for the production of nylon6 nanofibers for biomedical applications," Journal of Nanomaterials, vol. 2011, Article ID 626589, 8 pages, 2011.
[21] D. Lubosova and L. Martinova, "Controlled morphology of porous polyvinyl butyral nanofibres," Journal of Nanomaterials, vol. 2011, Article ID 292516, 6 pages, 2011.

[22] S. De Vrieze, P. Westbroek, T. Van Camp, and K. De Clerck, "Solvent system for steady state electrospinning of polyamide 6.6," Journal of Applied Polymer Science, vol. 115, no. 2, pp. 837-842, 2010.

[23] A. F. Spivak, Y. A. Dzenis, and D. H. Reneker, "Model of steady state jet in the electrospinning process," Mechanics Research Communications, vol. 27, no. 1, pp. 37-42, 2000.

[24] A. Suzuki and A. Endo, "Preparation of high modulus nylon 46 fibres by high-temperature zone-drawing," Polymer, vol. 38, no. 12, pp. 3085-3089, 1997.

[25] E. Vinken, A. E. Terry, O. Van Asselen, A. B. Spoelstra, R. Graf, and S. Rastogi, "Role of superheated water in the dissolution and perturbation of hydrogen bonding in the crystalline lattice of polyamide 4,6," Langmuir, vol. 24, no. 12, pp. 6313-6326, 2008.

[26] P. Adriaensens, A. Pollaris, R. Carleer et al., "Quantitative magnetic resonance imaging study of water uptake by polyamide 4,6," Polymer, vol. 42, no. 19, pp. 7943-7952, 2001.

[27] M. M. Bergshoef and G. J. Vancso, "Transparent nanocomposites with ultrathin, electrospun nylon-4,6 fiber reinforcement," Advanced Materials, vol. 11, no. 16, pp. 1362-1365, 1999.

[28] J. C. Uecker, G. C. Tepper, and J. Rosell-Llompart, "Ion-assisted collection of Nylon-4,6 electrospun nanofibers," Polymer, vol. 51, no. 22, pp. 5221-5228, 2010.

[29] P. Westbroek, T. Van Camp, S. De Vrieze, and K. De Clerck, PCT/EP2008/056050, 2008.

[30] B. De Schoenmaker, G. Annelies, L. Van der Schueren et al., "Study of polyamide 6.9 nanofibres under steady state conditions from a solvent/non-solvent solution," Journal Of Materials Science, vol. 47, no. 9, pp. 4118-4126, 2012.

[31] S. De Vrieze, B. De Schoenmaker, Ö. Ceylan et al., "Morphologic study of steady state electrospun polyamide 6 nanofibres," Journal of Applied Polymer Science, vol. 119, no. 5, pp. 2984-2990, 2011.

[32] W. Wei, J. T. Yeh, P. Li, M. R. Li, W. Li, and X. L. Wang, "Effect of nonsolvent on morphologies of polyamide 6 electrospun fibers," Journal of Applied Polymer Science, vol. 118, no. 5, pp. 3005-3012, 2010.

[33] L. Van Der Schueren, B. De Schoenmaker, O. I. Kalaoglu, and K. De Clerck, "An alternative solvent system for the steady state electrospinning of polycaprolactone," European Polymer Journal, vol. 47, no. 6, pp. 1256-1263, 2011.

[34] D. John, Lange's Handbook of Chemistry and Physics, MXGraw$\mathrm{Hi}, 15$ th edition, 1998.

[35] R. Nirmala, K. T. Nam, S. J. Park, Y. S. Shin, R. Navamathavan, and H. Y. Kim, "Formation of high aspect ratio polyamide6 nanofibers via electrically induced double layer during electrospinning," Applied Surface Science, vol. 256, no. 21, pp. 6318-6323, 2010.

[36] G. M. Kim, G. H. Michler, F. Ania, and F. J. B. Calleja, “Temperature dependence of polymorphism in electrospun nanofibres of PA6 and PA6/clay nanocomposite," Polymer, vol. 48, no. 16, pp. 4814-4823, 2007.

[37] A. Zajicova, K. Pokorna, A. Lencova et al., "Treatment of ocular surface injuries by limbal and mesenchymal stem cells growing on nanofiber scaffolds," Cell Transplantation, vol. 19, no. 10, pp. 1281-1290, 2010.

[38] J. Malašauskiene and R. Milašius, "Mathematical analysis of the diameter distribution of Electrospun nanofibres," Fibres and Textiles in Eastern Europe, vol. 83, no. 6, pp. 45-48, 2010. 
[39] K. H. Lee, H. Y. Kim, H. J. Bang, Y. H. Jung, and S. G. Lee, “The change of bead morphology formed on electrospun polystyrene fibers," Polymer, vol. 44, no. 14, pp. 4029-4034, 2003.

[40] S. Chuangchote, T. Sagawa, and S. Yoshikawa, "Electrospinning of poly(vinyl pyrrolidone): effects of solvents on electrospinnability for the fabrication of poly(p-phenylene vinylene) and $\mathrm{TiO}_{2}$ nanofibers," Journal of Applied Polymer Science, vol. 114, no. 5, pp. 2777-2791, 2009.

[41] S. Zhao, X. Wu, L. Wang, and Y. Huang, "Electrospinning of ethyl-cyanoethyl cellulose/tetrahydrofuran solutions," Journal of Applied Polymer Science, vol. 91, no. 1, pp. 242-246, 2004. 

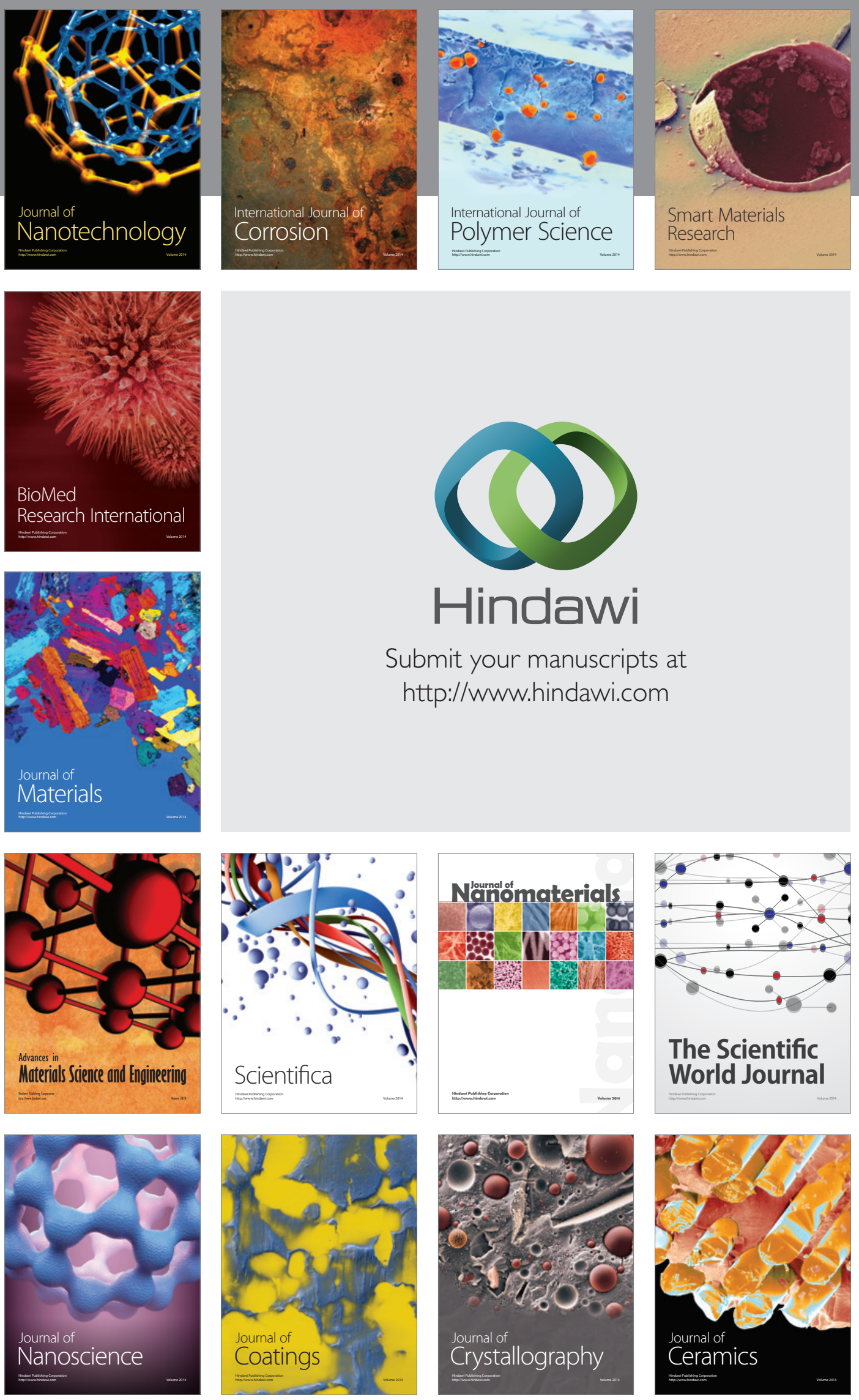

The Scientific World Journal

Submit your manuscripts at

http://www.hindawi.com

\section{World Journal}

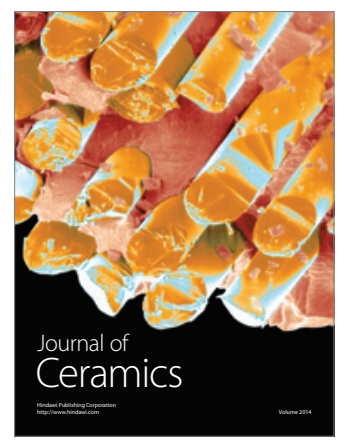

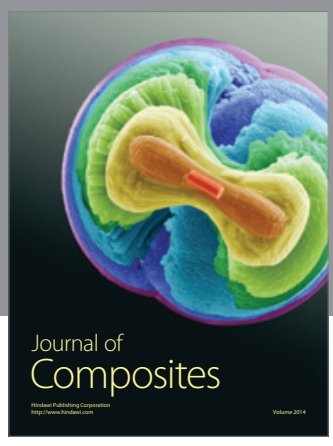
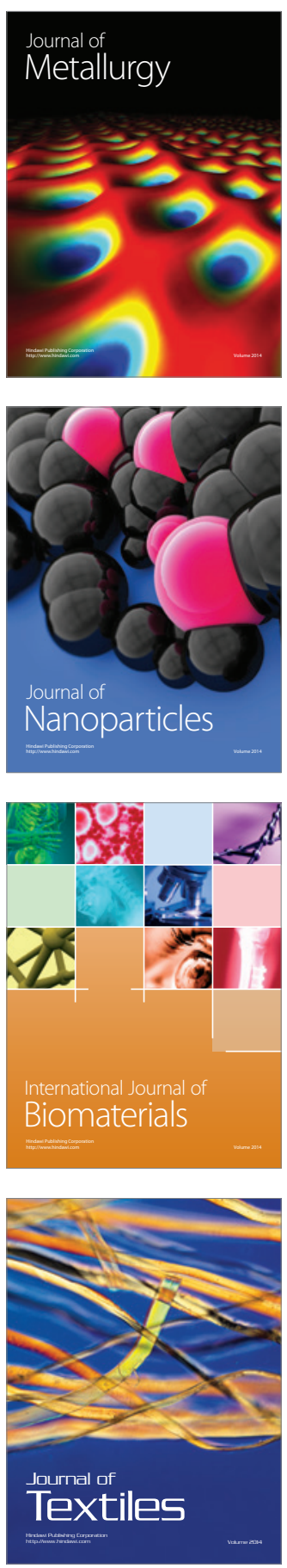